\title{
Less Anterior Knee Pain with a Mobile-bearing Prosthesis Compared with a Fixed-bearing Prosthesis
}

\author{
Stefan J. M. Breugem MD, Inger N. Sierevelt MSc, \\ Matthias U. Schafroth MD, PhD, Leendert Blankevoort PhD, \\ Gerard R. Schaap MD, PhD, C. Niek van Dijk MD, PhD
}

Received: 7 August 2007/Accepted: 13 May 2008/Published online: 4 June 2008

(C) The Author(s) 2008

\begin{abstract}
Anterior knee pain is one of the major shortterm complaints after TKA. Since the introduction of the mobile-bearing TKA, numerous studies have attempted to confirm the theoretical advantages of a mobile-bearing TKA over a fixed-bearing TKA but most show little or no actual benefits. The concept of self-alignment for the mobile bearing suggests the posterior-stabilized mobilebearing TKA would provide a lower incidence of anterior knee pain compared with a fixed-bearing TKA. We therefore asked whether the posterior-stabilized mobilebearing knee would in fact reduce anterior knee pain. We randomized 103 patients scheduled for cemented threecomponent TKA for osteoarthrosis in a prospective, double-blind clinical trial. With a 1-year followup, more patients experienced persistent anterior knee pain in the posterior-stabilized fixed-bearing group (10 of 53, 18.9\%) than in the posterior-stabilized mobile-bearing group (two of $47,4.3 \%$ ). No differences were observed for range of motion, visual analog scale for pain, Oxford 12-item questionnaire, SF-36, or the American Knee Society score. The posterior-stabilized mobile-bearing knee therefore seems to provide a short-term advantage compared with the posterior-stabilized fixed-bearing knee.
\end{abstract}

The institution of the authors has received funding from Zimmer bv, Amersfoort, The Netherlands.

Each author certifies that his or her institution has approved the human protocol for this investigation, that all investigations were conducted in conformity with ethical principles of research, and that informed consent for participation in the study was obtained.

S. J. M. Breugem $(\bowtie)$, I. N. Sierevelt, M. U. Schafroth, L. Blankevoort, G. R. Schaap, C. N. van Dijk Orthopaedic Research Center Amsterdam, Department of Orthopaedic Surgery, Academic Medical Center, PO Box 22660, 1100 DD Amsterdam, The Netherlands

e-mail: s.j.breugem@amc.uva.nl
Level of Evidence: Level I, therapeutic study. See the Guidelines for Authors for a complete description of levels of evidence.

\section{Introduction}

The TKA has become the generally accepted treatment for osteoarthritis of the knee $[1,4,6,9,12,13,28,30]$. The posterior cruciate-sacrificing total condylar prosthesis was introduced in 1978 [28]. This posterior-stabilized prosthesis has stood the test of time and has had long-term survival rates between $93 \%$ and $98.7 \%$ after 9 to 18 years followup $[9,12,13,28,30]$. This posterior-stabilized prosthesis can be considered the gold standard today relative to which new designs are matched $[9,12,13,28,30]$.

Although numerous studies emphasize long-term survival, short-term outcomes also are important to patients. Anterior knee pain is one of these issues: $4 \%$ to $49 \%$ of patients have anterior knee pain [2, 3, 23, 25, 29]. The pain reportedly does not decrease with time and restricts patients in climbing stairs, rising from a chair, cycling, or even normal walking $[3,4,24,25,31]$. Apart from being bothersome and impairing quality of life, anterior knee pain is one of the main reasons for early revision $[3,4,24$, $25,31]$.

There are a numerous theoretical benefits to the mobilebearing TKA, although few prospective, randomized studies have shown actual benefits [26]. One theoretical advantage is the ability to self-align and therefore to accommodate small errors in component placement. If this is true, then better patellar tracking might decrease the incidence of anterior knee pain.

We first asked whether the posterior-stabilized mobilebearing (PSM) knee prosthesis would lead to a lower 
incidence of anterior knee pain than the posterior-stabilized fixed-bearing (PS) knee prosthesis. We then asked whether one design would be superior to the other regarding overall pain, function, and quality of life.

\section{Materials and Methods}

Between November 2000 and July 2004, we considered 113 consecutive patients with unilateral osteoarthritis of the knee, scheduled for primary TKA, for participation in a prospective, double-blind, randomized clinical trial. Patients undergoing TKA were admitted 1 day before surgery for preoperative assessment. All patients older than 21 years, in otherwise good health and good candidates for surgery, and able to participate in the followup program were invited to participate. We excluded patients with revision or unilateral knee arthroplasty, patellectomy, a fixed varus or valgus deformity greater than $20^{\circ}$, skeletal immaturity, Charcot joints, unable or unwilling to cooperate in the followup program, life expectancy less than 5 years, or no signed informed consent. All 113 patients were willing to participate, but 10 were excluded owing to the previously mentioned exclusion criteria. We randomly allocated the remaining 103 patients to either a PS or PSM prosthesis. Block randomization was accomplished using a specially designed computer program developed by our institute's statistics department. The two patient groups were balanced based on age and, where applicable, previous operation, therefore ensuring approximately equally sized treatment groups. A power analysis was performed based on an estimated incidence of $25 \%$ of anterior knee pain $[1,2,4,6,23-26,29,31]$. We presumed a reduction of at least $10 \%$ should be obtained to achieve a successful reduction, in which $10 \%$ was the lower limit of the reported incidence creating an effect size of $15 \%$ [1, 2, 4, $6,23-26,29,31]$, stating a power of 0.8 with a 0.05 significance level resulting in a sample size of 100 patients per group. While performing an interim analysis, our study showed a difference in the incidence of anterior knee pain between the PS and PSM groups. Because our research question was answered, we stopped including patients in our study in July 2004. After 1 year, 100 of the 103 (97\%) patients were available for followup. One patient died the first postoperative day as a result of a cardiac event; one patient emigrated to the Dutch Antilles, and one patient withdrew from the study because of reasons not related to the prosthesis. The followup for all patients was 1 year ( \pm 2 months). The study was approved by the Internal Review Board. We obtained informed consent from each patient.

The demographic data were similar between the 55 patients in the PS group (20 males, 35 females) and the 48 patients in the PSM group (17 males, 31 females). The number of patients who lived at home and who lived independently or with someone was equal in both groups. The age of the patients who had a PS knee (mean, 68.9 years; range, 29-86 years) was similar to the age of those who had a PSM knee (mean, 71.2 years; range, 53-87 years). Body mass indices of the patients in the PS group and the PSM group were comparable, with means of $29.1 \mathrm{~kg} / \mathrm{m}^{2}$ (range, $21.0-46.1 \mathrm{~kg} / \mathrm{m}^{2}$ ) and $28.4 \mathrm{~kg} / \mathrm{m}^{2}$ (range, $18.4-56.6 \mathrm{~kg} / \mathrm{m}^{2}$ ), respectively. Both treatment groups were comparable preoperatively for anterior knee pain; 30 of the 48 patients with PSM knees $(62.5 \%)$ and 28 of the 43 patients with PS knees (65.1\%) had anterior knee pain.

The PS prosthesis was the NexGen ${ }^{\circledR}$ Complete Knee Solution Legacy ${ }^{\mathbb{R}}$ Posterior Stabilized Fixed Bearing Knee, whereas the PSM prosthesis was the NexGen ${ }^{\circledR}$ Complete Knee Solution Legacy ${ }^{\circledR}$ Posterior Stabilized Mobile Bearing Knee (both manufactured by Zimmer, Inc, Warsaw, IN). The PS and PSM prostheses share the same femoral component. The mobile-bearing polyethylene component is more congruent than that of the fixed-bearing prosthesis. The pivot axis of the articular surface is located anteriorly and allows rotation. The tibial plate includes a rotational stop that helps prevent spinout of the articular surface.

The surgery was performed by three experienced orthopaedic surgeons (CNvD, GRS, MUS), each with a special interest in TKA. The operations were performed using the same intraoperative protocol. General or spinal anesthesia and a preoperative dose of a second-generation cephalosporin $\left(\right.$ Zinacef ${ }^{\mathbb{R}}$; GlaxoSmithKline, Zeist, The Netherlands) were administered to all patients. All surgeons applied a tourniquet. A midline skin incision and a standard medial parapatellar approach were used in all patients. All patellae were everted to the lateral side. We first performed the horizontal tibial bone resection using an extramedullary alignment guide and then an intramedullary alignment guide was used for the femur. The desired angle was $7^{\circ}$ valgus and we used the transepicondylar axis to obtain $3^{\circ}$ external rotation relative to the posterior condyles. Patellae were treated by performing instrumented bone resection and removing osteophytes. Patients received a three-component cemented total knee prosthesis, ie, with a tibia component, femur component, and patella button. All patella buttons were identical with a three-pegged, polyethylene dome-shaped design. The patella buttons were cemented after the original thickness of the patella was restored or made slightly thinner. Optimal patellar tracking was ensured by appropriate soft tissue balancing. In all patients with tightness of the lateral retinaculum, producing subluxation of the patella, the "no thumb" rule was performed. When there was still doubt, the tourniquet 
was deflated and the patella tracking reassessed; only then was release of the lateral retinaculum performed. Lateral retinacular release was performed in four $(7.7 \%)$ of the PS knees and in four $(8.3 \%)$ of the PSM knees. There was no difference in size of the polyethylene insert between the PS group (mean, 11.4, range, 9-17) and the PSM group (mean, 11.5; range, 10-17). In both groups, one Size 17 polyethylene was required to achieve sufficient stability. A lowvacuum drain was used for 24 hours for all patients.

All patients received the same postoperative treatment. On the second postoperative day, they began continuous passive motion. For prophylaxis, the patients were given a low-molecular-weight heparin (Fraxiparine $^{\circledR}$; SanofiSynthélabo, Maassluis, The Netherlands) for 4 weeks. The physiotherapist was involved from the first postoperative day. Hospital discharge occurred when the patient was able to bend the knee actively in greater than $90^{\circ}$ flexion and walk independently with crutches. After being discharged, physiotherapy was continued at home, improving function and independent walking.

Followup controls occurred at 6 weeks, 3 months, 6 months, and 12 months postoperatively, including standard radiographs and physical examinations. Preoperative and 1-year postoperative, standardized subjective questionnaires were completed.

At the time this study was instituted, no scoring system for measuring anterior knee pain had been validated [2]. Rather, the patients were questioned (by SJMB, DH, MA, $\mathrm{RN}$ ) regarding the location of any pain in the knee; none of these evaluators were involved in the surgery and none were aware of the treatment. To determine the presence and severity of anterior knee pain, the following questions were used: "Do you have anterior knee pain?" or "Does the pain of your knee get worse when standing up from a chair, climbing stairs, or riding a bicycle against the wind?" The severity was classified by using the stairclimbing portion of the American Knee Society score as (1) none, (2) mild, (3) moderate, and (4) severe. In addition to the specific questions asked, we incorporated the SF-36 (Question 7), the stair-climbing and pain portion of the American Knee Society score, and the Oxford 12-item questionnaire concerning climbing stairs and standing up from a chair [11, 15]. Additionally, a thorough clinical evaluation was performed.

At the preoperative intake and after 1 year ( \pm 2 months $)$, patients completed questionnaires containing visual analog scores (VAS), the Oxford 12-item questionnaire, and the SF-36. We obtained VAS scores, with a range of 0 to 100 , to assess current knee pain and the overall average knee pain during a 4-week period. The Oxford 12-item questionnaire is a knee-specific questionnaire to determine knee function, with a range of 12 to $60[11,15]$. The SF-36 is a general health-related quality of life instrument [16]. Thirty-six questions reflect eight dimensions of functioning, with a range of 0 to 100 . Higher scores indicate a better quality of life.

We (SJMB, DH, MA, RN) performed a clinical evaluation using the American Knee Society score [18] to determine function, pain, range of motion (ROM), and stability of the knee; none of these evaluators were involved in the surgery and none were aware of the treatment. This score ranges from 0 to 200 and can be divided into a knee score and a function score. A higher score implies a better outcome.

Preoperative and postoperative radiographs of the knee were obtained in standing anteroposterior, lateral, and Merchant views (skyline of the patellofemoral joint). All radiographs of the knee were reviewed by one of the authors (SJMB) and a radiologist specialized in skeletal radiology; both were blinded to outcome but could not be blinded to the type of prosthesis. The Knee Society Total Knee Arthroplasty Roentgenographic Evaluation and Scoring System was used postoperatively and at 1-year followup to determine the varus-valgus angle, signs of early loosening, or wear of the prosthesis. The fluoroscopic imaging in anteroposterior and lateral views was used to study component interfaces for an increase in radiolucent lines indicating loosening. The average preoperative femorotibial angle was $3.9^{\circ}$ varus, with a range of $14^{\circ}$ varus to $19^{\circ}$ valgus. In the PS group, this was $3.8^{\circ}$ varus, and in the PSM group, this was $4.0^{\circ}$. Postoperatively, the average femorotibial angle was $6.9^{\circ}$ valgus, with a range of $0.8^{\circ}$ to $11.7^{\circ}$ valgus. There were no differences between the PS group $\left(6.7^{\circ}\right)$ and the PSM group $\left(7.0^{\circ}\right)$. There were no clear signs of early loosening or polyethylene wear.

All complications were divided into intraoperative, general, and local complications and into early (first 3 months) and late (3-12 months) complications.

Data were entered in a personal computer (Microsoft ${ }^{\circledR}$ Access 2000; Microsoft Corp, Redmond, WA) by an independent research assistant (INS) and subsequently were checked for inconsistencies and errors in data entry. As the continuous data did not have normal distributions (Kolmogorov-Smirnov test, $\mathrm{p}<0.05$ ), we used nonparametric analyses. At baseline, differences between the PS and PSM groups were assessed for age and body mass index using Mann-Whitney $U$ tests, and categorical data, such as gender, independence, and anterior knee pain, were compared using chi square tests. Preoperatively and postoperatively, comparisons between the groups were made for ROM, American Knee Society knee score, American Knee Society function score, VAS scores, Oxford 12-items score, and SF-36 quality of life scores using Mann-Whitney $\mathrm{U}$ tests, and changes from baseline at 1 year followup were assessed using Wilcoxon signed-ranks tests. To compare the prevalence of anterior knee pain between the PS and 
PSM groups, Fisher's exact test was performed. Differences between results of patients with and without anterior knee pain were determined for the VAS scores, Oxford 12-item score, American Knee Society function, and American Knee Society knee score using Mann-Whitney U tests. Categorical variables, such as knee pain at rest, pain during walking, pain during walking up and down stairs, function walking, function walking stairs, and walking aids were compared using chi square tests. Statistical analysis was performed using SPSS 12.1 (SPSS Inc., Chicago, IL).

\section{Results}

One year postoperatively, patients with PSM prostheses had less $(p=0.03)$ mean anterior knee pain than patients with PS prostheses. Two of the 47 patients $(4.3 \%)$ with PSM prostheses and 10 of the 53 patients (18.9\%) with PS prostheses experienced persistent anterior knee pain (Fig. 1). The severity of anterior knee pain experienced by the patients with PSM prostheses (one severe, one moderate) and PS prostheses (four severe, four moderate, two mild) was comparable. There was no difference regarding obesity, gender, or patients who had anterior knee pain at baseline and who postoperatively reported anterior knee pain. Patients with anterior knee pain scored lower on the American Knee Society score $(\mathrm{p}<0.001)$ and Oxford 12 -item knee questionnaire $(\mathrm{p}=0.04)$ than patients without anterior knee pain (Table 1).

In both groups, the VAS related to the current pain and overall average knee pain during a 4-week period in the affected knee improved $(\mathrm{p}<0.001)$ postoperatively (Table 2). However, at the 1-year followup, these improvements were similar $(\mathrm{p}=0.78)$. We observed no differences

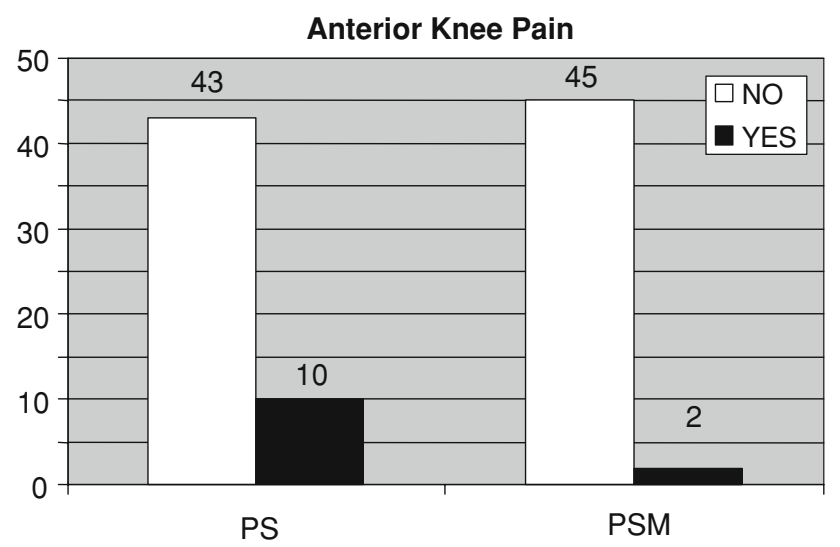

Fig. 1 A graph shows the number of patients who reported having no anterior knee pain (negative) or experiencing anterior knee pain (positive) in the two groups that had a posterior-stabilized fixedbearing prosthesis (PS; $\mathrm{n}=53$ ) or a posterior-stabilized mobilebearing prosthesis (PSM; $\mathrm{n}=47$ ) implanted during TKA. in postoperative pain at rest, pain with walking, and pain after climbing stairs, walking ability, the ability to climb or descend stairs, or the use of walking aids.

There was similar $(\mathrm{p}=0.60)$ postoperative improvement in function for patients with the PS and PSM prostheses. The ROM had improved $(p=0.77)$ in both groups at 1 year postoperatively, but the improvement was similar in the two groups (Table 2). The preoperative and postoperative clinical scores did not correlate $(r=0.27$, $\mathrm{p}=0.005)$, reflecting independence of the responses before and after surgery.

The quality of life measures were similar ( $p$ value ranging from 0.28 to 0.88 ) between patients with PSM and PS prostheses. Patients with anterior knee pain reported lower levels of quality of life than patients without anterior knee pain (Table 1).

Perioperative complications included two partial medial collateral ligament ruptures in the PS group. These patients were treated with a brace for 6 weeks resulting in a stable knee in both patients. Postoperative complications occurred in six patients in each group. Patellar fractures, dislocations, or loose patellar components were not observed. Three patients had a hematoma that was surgically débrided (one PSM, two PS). There were no deep or superficial infections. Six patients (three in each group) needed manipulation under anesthesia to achieve $90^{\circ}$ flexion. After this procedure, one PS knee continued to have only $40^{\circ}$ flexion. Preoperatively, this patient had flexion of $20^{\circ}$. General complications occurred in seven patients. One patient needed a pacemaker and one needed medication because of heart rhythm disorders. Another patient was treated with anticoagulation for 3 months for a nonfatal lung embolism. Three patients were treated for urinary tract infections and one patient was treated for pneumonia.

\section{Discussion}

The presence of anterior knee pain is one of the major short-term complaints after TKA [1, 2, 9, 22, 24-26, 29, 31]. Published reports show between $4 \%$ and $49.2 \%$ of all patients have anterior knee pain [1, 2, 9, 22, 24-26, 29, 31]. Since the introduction of the mobile-bearing prosthesis, numerous studies have been performed, each comparing different aspects of the hypothesized advantage of using a mobile-bearing prosthesis compared with a fixed-bearing prosthesis $[1,5,6,9,10,14,17,19-22,24-27,31,32]$. The theoretical advantage of the mobile-bearing prosthesis is the ability to self-align and therefore to accommodate small mismatches, which could lead to a decrease in the incidence of anterior knee pain [1, 9, 24]. Our study was performed to determine if the PSM could in fact decrease the incidence and severity of reported anterior knee pain. 
Table 1. Comparison of patients with and without anterior knee pain

\begin{tabular}{llrr}
\hline Test & Anterior knee pain $(\mathrm{n}=12)$ & No anterior knee pain $(\mathrm{n}=88)$ & $\mathrm{p}$ value \\
\hline VAS current & 42.2 & 15.3 & 19.7 \\
VAS last month & 47.9 & 23.6 & $0.001^{*}$ \\
Oxford 12-item questionnaire & 32.1 & 49.8 & $0.044^{*}$ \\
SF-36 Q1 (physical functioning) & 44.2 & 63.9 & 0.415 \\
SF-36 Q7 (pain) & 51.6 & 64.4 & 0.218 \\
American Knee Society function & 51.3 & 85.6 & 0.368 \\
American Knee Society knee score & 65.3 & $6.8 \%$ & $7.1 \%$ \\
Knee pain at rest (mild/severe pain) & $50 \%$ & $12.5 \%$ & $<0.001^{*}$ \\
Knee pain walking (mild/severe pain) & $58.4 \%$ & $64.7 \%$ \\
Knee pain walking up and down stairs (mild/severe pain) & $75 \%$ & $31.8 \%$ \\
Function walking (mild/severe) & $33.3 \%$ & $<0.001^{*}$ \\
Function walking stairs (normal or support walking down the stairs) & $16.6 \%$ & $64.8 \%$ \\
Walking aids & $58.3 \%$ & $<0.001^{*}$ \\
\hline
\end{tabular}

* Significantly different at $\mathrm{p}<0.05$; VAS $=$ visual analog scale.

Table 2. Preoperative and postoperative comparisons

\begin{tabular}{|c|c|c|c|c|}
\hline \multirow[t]{2}{*}{ Score } & \multicolumn{2}{|c|}{ PS $(n=53)$} & \multicolumn{2}{|c|}{$\operatorname{PSM}(n=47)$} \\
\hline & Mean & $95 \% \mathrm{CI}$ & Mean & $95 \% \mathrm{CI}$ \\
\hline \multicolumn{5}{|l|}{ Preoperative } \\
\hline Range of motion & $112^{\circ}$ & $80^{\circ}-140^{\circ}$ & $107.5^{\circ}$ & $75^{\circ}-140^{\circ}$ \\
\hline American Knee Society knee score & 52.7 & $46.1-59.2$ & 53 & $46.9-59.2$ \\
\hline American Knee Society function score & 41.2 & $33.4-49$ & 43 & $33.9-52$ \\
\hline VAS current & 57.2 & $48.7-65.7$ & 53.4 & $44.7-62.1$ \\
\hline VAS last month & 63.4 & $55.7-71.7$ & 63 & $55.2-71.0$ \\
\hline Oxford 12 -item questionnaire & 36.3 & $32.6-39.7$ & 38.4 & $34.4-42.6$ \\
\hline \multicolumn{5}{|l|}{ Postoperative } \\
\hline Range of motion & $111.7^{\circ}$ & $106.6^{\circ}-116.8^{\circ}$ & $113.3^{\circ}$ & $108^{\circ}-118.6^{\circ}$ \\
\hline American Knee Society knee score & 82.7 & $77-88.4$ & 83.2 & $77.5-88.8$ \\
\hline American Knee Society function score & 65 & $56-74$ & 60.8 & $49.1-72.4$ \\
\hline VAS current & 21.9 & $13.2-29$ & 19.2 & $12.2-26.2$ \\
\hline VAS last month & 25.7 & $16.6-34.8$ & 23.5 & $15.9-31.0$ \\
\hline Oxford 12-item questionnaire & 24.2 & $21.2-27.2$ & 26.1 & $22.3-29.8$ \\
\hline SF-36 Q1 & 16.5 & & 18.2 & \\
\hline SF-36 Q2 & 29.7 & & 32.4 & \\
\hline SF-36 Q3 & 5.8 & & 12.8 & \\
\hline SF-36 Q4 & 12.3 & & 17.2 & \\
\hline SF-36 Q5 & 0.8 & & 3.8 & \\
\hline SF-36 Q6 & 2.9 & & 10.2 & \\
\hline SF-36 Q7 & 25.9 & & 24.6 & \\
\hline SF-36 Q8 & -3.6 & & -6.4 & \\
\hline
\end{tabular}

Preoperative and postoperative values are not significantly different at $\mathrm{p}>0.05$; PS $=$ posterior-stabilized fixed-bearing; PSM $=$ posteriorstabilized mobile-bearing; $\mathrm{CI}=$ confidence interval; VAS = visual analog scale; $\mathrm{Q} 1=$ physical functioning; Q2 = role limitation due to physical problems; Q3 = role limitation due to emotional problems; Q4 = social functioning; Q5 = mental health; Q6 = energy vitality; $\mathrm{Q} 7$ = pain; Q8 = general health perception.

We followed our patients for a minimum of 1 year. "Aglietti et al. suggested that the performance of a mobilebearing design may decline over time [1]." However, because anterior knee pain is relevant to patients in the short and long term, we do not believe this is a limitation [26]. We did have relatively small sample sizes, but the 
data show a difference in the incidence of anterior knee pain between the PS and PSM prostheses. We did not have a standardized, validated instrument specifically for anterior knee pain, but we presume our focused questions identified the presence and approximate severity of the pain. We studied only two specific devices from one manufacturer and do not presume they would be generalizable to other fixed- and mobile-bearing prostheses. The study was not designed primarily to detect functional differences and the power may have been too low to detect such a difference.

We found less anterior knee pain in patients with the PSM prosthesis than with the PS prosthesis. Price et al. [26] reported better American Knee Society scores and Oxford 12-item questionnaire and pain scores for mobile-bearing prostheses 1 year after placing bilateral mobile-bearing and fixed-bearing prostheses in 40 patients. One study reported a mobile-bearing prosthesis resulted in a high rate of anterior knee pain $(49.2 \%)$ attributable to a suboptimal trochlear design [25]. As reported by others, we found these subjective outcome scores improved from baseline for patients in both groups; however, we observed no difference between the two types of prostheses (Table 1).

Theoretically, the design of the PSM prosthesis could lead to better ROM during knee flexion activities [14]. We observed no difference in ROM between patients in either group. The patients in both groups reached a mean ROM greater than $110^{\circ}$, which is comparable to reported ranges and is sufficient for normal daily functioning [24]. Anterior knee pain is known to cause difficulties in daily activities such as climbing stairs, rising from a chair, getting in and out of a car, or cycling, and therefore compromise these activities [24-26]. We evaluated the postulated advantage of the PSM compared with the PS knees but could not discern any difference except the decrease in anterior knee pain. As reported by others, we also found no difference in the short-term functional outcome between fixed- and mobile-bearing designs [24].

The incidence of lateral retinacular release reportedly has decreased with the use of a mobile-bearing design (from $10 \%$ for the fixed-bearing prosthesis to $0 \%$ for the mobile-bearing prosthesis); however, in our study, the incidence was identical in both groups, confirming the findings in two other studies [24, 27].

Subjective questionnaires are essential instruments to evaluate our operative results $[7,8,11,15,18]$. Quality of life can be influenced by many factors and not only the ones tested in our study [8]. We detected no difference in quality of life between patients with PSM and PS prostheses, but we could detect the influence of anterior knee pain on the general subjective health questionnaires and also on the knee-specific questionnaires (Table 1). Patients with anterior knee pain reported lower levels of quality of life than patients without anterior knee pain. Our data support the notion that the PSM prosthesis reduces the short-term incidence of anterior knee pain relative to the PS prosthesis. Longer followup will determine whether this difference will persist or decrease.

Acknowledgments We thank Daniel Haverkamp, MD, PhD, Rudolf W. Poolman, MD, PhD, Robert P. Berg, MD, Mark Altena, MD, and Raymond Nelis, MD, for help in designing and conducting the study.

Open Access This article is distributed under the terms of the Creative Commons Attribution Noncommercial License which permits any noncommercial use, distribution, and reproduction in any medium, provided the original author(s) and source are credited.

\section{References}

1. Aglietti P, Baldini A, Buzzi R, Lup D, De Luca L. Comparison of mobile-bearing and fixed-bearing total knee arthroplasty: a prospective randomized study. J Arthroplasty. 2005;20:145-153.

2. Baldini A, Anderson JA, Zampetti P, Pavlov H, Sculco TP. A new patellofemoral scoring system for total knee arthroplasty. Clin Orthop Relat Res. 2006;452:150-154.

3. Barrack RL, Schrader T, Bertot AJ, Wolfe MW, Myers L. Component rotation and anterior knee pain after total knee arthroplasty. Clin Orthop Relat Res. 2001;392:46-55.

4. Barrack RL, Wolfe MW, Waldman DA, Milicic M, Bertot AJ, Myers L. Resurfacing of the patella in total knee arthroplasty: a prospective, randomized, double-blind study. J Bone Joint Surg Am. 1997;79:1121-1131.

5. Bhan S, Malhotra R, Kiran EK, Shukla S, Bijjawara M. A comparison of fixed-bearing and mobile-bearing total knee arthroplasty at a minimum follow-up of 4.5 years. J Bone Joint Surg Am. 2005;87:2290-2296.

6. Biau D, Mullins MM, Judet T, Piriou P. Mobile versus fixedbearing total knee arthroplasty: mid-term comparative clinical results of 216 prostheses. Knee Surg Sports Traumatol Arthrosc. 2006;14:927-933.

7. Boeckstyns ME, Backer M. Reliability and validity of the evaluation of pain in patients with total knee replacement. Pain. 1989;38:29-33.

8. Brander VA, Stulberg SD, Adams AD, Harden RN, Bruehl S, Stanos SP, Houle T. Predicting total knee replacement pain: a prospective, observational study. Clin Orthop Relat Res. 2003; 416:27-36

9. Callaghan JJ, Insall JN, Greenwald AS, Dennis DA, Komistek RD, Murray DW, Bourne RB, Rorabeck CH, Dorr LD. Mobilebearing knee replacement: concepts and results. Instr Course Lect. 2001;50:431-449.

10. Chiu KY, Ng TP, Tang WM, Lam P. Bilateral total knee arthroplasty: one mobile-bearing and one fixed-bearing. J Orthop Surg (Hong Kong). 2001;9:45-50.

11. Dawson J, Fitzpatrick R, Murray D, Carr A. Questionnaire on the perceptions of patients about total knee replacement. J Bone Joint Surg Br. 1998;80:63-69.

12. Diduch DR, Insall JN, Scott WN, Scuderi GR, Font-Rodriguez D. Total knee replacement in young, active patients: long-term follow-up and functional outcome. $J$ Bone Joint Surg Am. 1997;79:575-582. 
13. Duffy GP, Trousdale RT, Stuart MJ. Total knee arthroplasty in patients 55 years old or younger: 10- to 17-year results. Clin Orthop Relat Res. 1998;356:22-27.

14. Haas BD, Komistek RD, Stiehl JB, Anderson DT, Northcut EJ. Kinematic comparison of posterior cruciate sacrifice versus substitution in a mobile bearing total knee arthroplasty. J Arthroplasty. 2002;17:685-692.

15. Haverkamp D, Breugem SJ, Sierevelt IN, Blankevoort L, van Dijk CN. Translation and validation of the Dutch version of the Oxford 12-item knee questionnaire for knee arthroplasty. Acta Orthop. 2005;76:347-352.

16. Hawker G, Melfi C, Paul J, Green R, Bombardier C. Comparison of a generic (SF-36) and a disease specific (WOMAC) (Western Ontario and McMaster Universities Osteoarthritis Index) instrument in the measurement of outcomes after knee replacement surgery. J Rheumatol. 1995;22:1193-1196.

17. Henricson A, Dalen T, Nilsson KG. Mobile bearings do not improve fixation in cemented total knee arthroplasty. Clin Orthop Relat Res. 2006;448:114-121.

18. Insall JN, Dorr LD, Scott RD, Scott WN. Rationale of the Knee Society clinical rating system. Clin Orthop Relat Res. 1989;248:13-14.

19. Kim YH, Yoon SH, Kim JS. The long-term results of simultaneous fixed-bearing and mobile-bearing total knee replacements performed in the same patient. J Bone Joint Surg Br. 2007; 89:1317-1323.

20. Maniar R. Rationale for the posterior-stabilized rotating-platform knee. Orthopedics. 2006;29(9 suppl):S23-S27.

21. Most E, Li G, Schule S, Sultan P, Park SE, Zayontz S, Rubash HE. The kinematics of fixed- and mobile-bearing total knee arthroplasty. Clin Orthop Relat Res. 2003;416:197-207.

22. Muoneke HE, Khan AM, Giannikas KA, Hagglund E, Dunningham TH. Secondary resurfacing of the patella for persistent anterior knee pain after primary knee arthroplasty. $J$ Bone Joint Surg Br. 2003;85:675-678.
23. Murray DW, Frost SJ. Pain in the assessment of total knee replacement. J Bone Joint Surg Br. 1998;80:426-431.

24. Pagnano MW, Trousdale RT, Stuart MJ, Hanssen AD, Jacofsky DJ. Rotating platform knees did not improve patellar tracking: a prospective, randomized study of 240 primary total knee arthroplasties. Clin Orthop Relat Res. 2004;428:221-227.

25. Popovic N, Lemaire R. Anterior knee pain with a posteriorstabilized mobile-bearing knee prosthesis: the effect of femoral component design. J Arthroplasty. 2003;18:396-400.

26. Price AJ, Rees JL, Beard D, Juszczak E, Carter S, White S, de Steiger R, Dodd CA, Gibbons M, McLardy-Smith P, Goodfellow JW, Murray DW. A mobile-bearing total knee prosthesis compared with a fixed-bearing prosthesis: a multicentre single-blind randomised controlled trial. J Bone Joint Surg Br. 2003;85: 62-67.

27. Ranawat AS, Rossi R, Loreti I, Rasquinha VJ, Rodriguez JA, Ranawat CS. Comparison of the PFC Sigma fixed-bearing and rotating-platform total knee arthroplasty in the same patient: short-term results. J Arthroplasty. 2004;19:35-39.

28. Scuderi GR, Clarke HD. Cemented posterior stabilized total knee arthroplasty. J Arthroplasty. 2004;19(4 suppl 1):17-21.

29. Scuderi GR, Insall JN, Scott NW. Patellofemoral pain after total knee arthroplasty. J Am Acad Orthop Surg. 1994;2: 239-246.

30. Stern SH, Insall JN. Posterior stabilized prosthesis: results after follow-up of nine to twelve years. J Bone Joint Surg Am. 1992;74:980-986.

31. Wood DJ, Smith AJ, Collopy D, White B, Brankov B, Bulsara MK. Patellar resurfacing in total knee arthroplasty: a prospective, randomized trial. J Bone Joint Surg Am. 2002;84:187-193.

32. Woolson ST, Northrop GD. Mobile- vs. fixed-bearing total knee arthroplasty: a clinical and radiologic study. J Arthroplasty. 2004;19:135-140. 